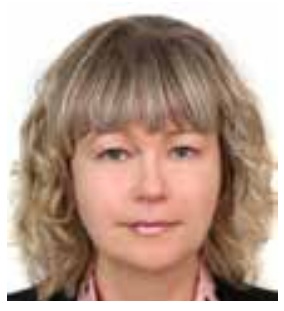

Александра Александровна ГАЙВОРОНСКАЯ,

инспектор отдела исследования проблем технико-криминалистического и экспертного сопро-

вождения расследования преступлений Управления НИД

(НИИ криминалистики)

ГУК (Криминалистического центра) Следственного комитета Российской Федерации, кандидат психологических наук, доцент agajvoronskaya@yandex.ru 105005, Россия, г. Москва, Технический пер., д. 2

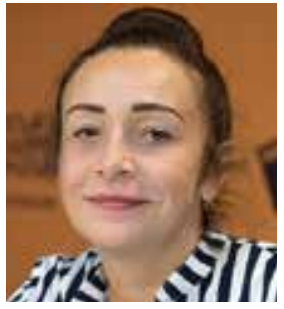

Елена Николаевна ХОЛОПОВА,

профрессор кафедры уголовного процесса, криминалистики

и правовой информатики Юридического института Балтийского федерального университета имени И. Канта, доктор юридических наук, кандидат психологических наук, профрессор elchol@mail.ru 236016, Россия, 2. Калининград, пл. Маршала Василевского, д. 2

(C) А. А. Гайворонская, Е. Н. Холопова, 2021

\section{ОСОБЕННОСТИ ТАКТИЧЕСКИХ ПРИЕМОВ ДОПРОСА ПО ПРЕСТУПЛЕНИЯМ ЭКСТРЕМИСТСКОЙ НАПРАВЛЕННОСТИ, СОВЕРШЕННЫМ В СЕТИ ИНТЕРНЕТ}

\begin{abstract}
Аннотация. Рассматриваются особенности тактических приемов при ведении допроса по преступлениям экстремистской направленности, совершенным в сети Интернет. Интернет-пространство выступает такой социальной средой, которая конгруэнтна (привлекательна) для адептов экстремистской деятельности, где их ведущая характеристика - это направленность на нетипичное, ненормативное, асоциальное поведение. Тактические приемы допроса создают условия для получения показаний об обстоятельствах дела: был ли призыв к насилию, оправдывается ли насилие, каково содержание материалов, представленных в сети, какие средства (плакаты, листовки и др.) применялись.

При ведении допроса использование приемов психологического воздействия облегчает получение криминалистически значимой информации. Для лиц, совершающих преступления экстремистской направленности, с учетом типизации личностных особенностей (идеалистический тип, ненормативный, искатель приключений) описаны некоторые эфрорективные тактические приемы (выход эмоций, обнаженная агрессия, обмен позициями, вмешательство авторитетного третьего и др.) с примерным перечнем вопросов. Приемы предназначены для достижения взаимопонимания между следователем и допрашиваемым, при которых последний, независимо от складывающейся ситуации, сотрудничает со следователем и представляет инфоормацию об обстоятельствах дела без искажения и сокрытия. Ключевые слова: преступления экстремистской направленности, уголовное судопроизводство, следственные действия, криминалистическая тактика, допрос, тактический прием, психологическое воздействие, интернет-пространство.
\end{abstract}

DOI: 10.17803/2311-5998.2021.78.2.060-068 


\title{
A. A. GAIVORONSKAYA,
}

inspector of the research Department of technical-criminalistic and expert support of crime investigation of the Investigative Committee of the Russian Federation,

Cand. Sci. (Psychology), Associate Professor agajvoronskaya@yandex.ru

105005, Russia, Moscow, Tekhnicheskij per., 2

E. N. KHOLOPOVA, Professor of the Department of criminal procedure, criminalistics and legal informatics of the Law Institute of the Kant Baltic Federal University, Dr. Sci. (Law), Cand. Sci. (Psychology), Professor elchol@mail.ru 236016, Russia, Kaliningrad, Marshal Vasilevsky pl., 2

TACTICAL INTERROGATION TECHNIQUES FOR EXTREMIST CRIMES COMMITTED ON THE INTERNET

\begin{abstract}
The article deals with the peculiarities of tactical techniques for conducting interrogations on extremist crimes committed on the Internet. The Internet space acts as a social environment that is congruent (attractive) for adherents of extremist activities, where their leading characteristic is a focus on atypical, non - normative, asocial behavior. Tactical interrogation techniques create conditions for obtaining evidence about the circumstances of the case: whether there was a call to violence, whether violence is justified, what is the content of the materials presented in the network, what means (posters, leaflets, etc.) were used. When conducting an interrogation, the use of psychological influence techniques makes it easier to obtain criminally significant information. For individuals who commit crimes of extremist orientation, taking into account the typification of personal characteristics (idealistic, adventurers, non-normative), some effective tactics are described (egress to emotions, naked aggression, exchange of positions, intervention of an authoritative third, etc.) with an approximate list of questions. Techniques are designed to achieve mutual understanding between the investigator and the interrogated, in which the latter, regardless of the current situation, cooperates with the investigator and provides information about the circumstances of the case without distortion or concealment.
\end{abstract}

Keywords: extremist crimes, criminal proceedings, investigative actions, forensic tactics, interrogation, tactical techniques, psychological impact, Internet space.

следственной практике существует потребность в тактических приемах допроса по преступлениям экстремистской направленности, совершенным в сети Интернет, которая обусловлена личностными характеристиками пользователей киберпространства. Ведущая личностная характеристика таких 
пользователей - это направленность на нетипичное, ненормативное, асоциальное поведение.

Интернет-пространство выступает такой социальной средой, которая конгруэнтна (привлекательна) для адептов экстремистской деятельности, потому что дублирует и (или) моделирует социальную действительность. В рамках этого пространства создаются различные виртуальные конструкции, формирующие у личности желанную картину мира.

Использование киберпространства экстремистскими организациями для пропаганды (максимального распространения своих идей), для вербовки и подстрекательства, для подготовки/обучения, планирования и координации деятельности и финансирования экстремистских организаций определяется ультрасовременными информационными и телекоммуникационными технологиями.

Тактические приемы допроса создают условия для получения показаний об обстоятельствах дела: был ли призыв к насилию, оправдывается ли насилие, каково содержание материалов, представленных в сети, какие средства (плакаты, листовки и др.) применялись. Изучение данных, связь содержания контента с конкретными лицами, с тематическими сайтами, социальными сетями, чатами, форумами, а также рассмотрение различных сообществ в мессенджерах (напримep, Telegram), представляющих и отображающих экстремистский материал, используется в качестве доказательств (по результатам заключения экспертов, специалистов).

Данные тактические приемы допроса в психологическом аспекте содержат разные способы воздействия на психику допрашиваемого. Психологическое воздействие-это способы влияния (убеждение, внушение и др.) на психику допрашиваемого для получения достоверных показаний. Считается, что психологическое воздействие - профессиональная часть деятельности следователя,

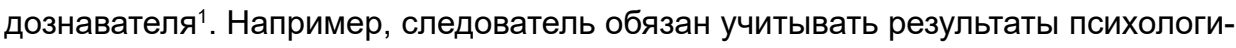
ческого воздействия, которые являются скрытыми, незаметными, проводимыми через организованную следователем ситуацию, побуждающую допрашиваемого к желательным поступкам².

Использование психологического воздействия при проведении допроса корректно при следующих условиях: для создания атмосферы сотрудничества между допрашиваемым и допрашивающим и для получения информации без сокрытия и ее искажения. Критерии допустимости применения психологического воздействия при проведении допроса определены в УПК РФ. При этом важно, что следователь не может задавать наводящие вопросы (это запрещено) ${ }^{3}$, зато выбор

1 Козлова Н. И. Психологические приемы допроса при расследовании оскорблений // Психопедагогика в правоохранительных органах. 2010. № 4 (43). С. 24-26.

2 Черевко И. М., Никонович С. Л., Бекетов В. А. Системный подход к психологическому воздействию следователя на допрашиваемого // Крымский научный вестник. 2017. № 1. C. $75-89$.

3 Об особенностях формирования наводящих вопросов см.: Комиссаров В. И., Комиссарова Я. В. Тактика допроса и очной ставки // Криминалистика : учебник (уровень специалитета) / под ред. А. И. Бастрыкина, Е. П. Ищенко, Я. В. Комиссаровой. М. : Проспект, 2019. C. 397. 
тактики и приемов воздействия на допрашиваемого остается на усмотрение следователя (ч. 2 ст. 189 УПК РФ).

По мнению Е. В. Васкэ, «при условии правомерности психологическое воздействие в ходе расследования является как раз тем средством, которое в конечном итоге поможет достичь профессионально важных целей уголовного судопроизводства, к которым в первую очередь относится вынесение законного наказания виновному через установление истины по уголовному делу» ${ }^{4}$. Если в действиях следователя применяемое психологическое воздействие носит характер принуждения (насилия), то в этих действиях содержатся признаки состава преступления, предусмотренного ч. 1 ст. 302 УК РФ (принуждение к даче показаний).

Психологическое воздействие с опорой на эмоции является внушением, а с опорой на сознание трансформируется в убеждения. Употребление в следственной практике убеждения связано с аргументами, фактами, обоснованием позиции следователя. Внушение используется для создания психологического контакта, для донесения информации до допрашиваемого без его критического отношения.

Учитывая специфику (корректность применения) такого психологического воздействия, как внушение, в условиях проведения допроса важно понимать, что в основе этого воздействия лежит мера восприятия информации у допрашиваемого, отражающая ярко выраженные его индивидуальные различия. К ним относятся проявления конформизма (поступки, поведение допрашиваемого совпадают с его окружением), психического заражения (подражание авторитету: И. В. Сталин, команданте Че Гевара), делегирование ответственности (проявляется утверждение, что отвечать за свои поступки придется потом, в далеком будущем или перед Богом), ролевое взаимодействие (при допросе изменяются роли: «хитрец», «умник», «герой» и др.) и социальная включенность (адаптированность к окружению, востребованность).

Результаты проведенных ранее исследований, изучение материалов уголовных дел по преступлениям экстремистской направленности позволили выделить три группы лиц, совершающих такое преступное деяние, как экстремизм5. Полученная классификация (типология) построена на основе учета особенностей поведения, характеристик личности:

1. Просоциальный/идеалистический тип (интеллектуалы). Его представители выступают за установление идеалов справедливости, борьбы против неравенства: их отличают активная позиция, альтруистические установки, протест против агрессивной внешней или внутренней политики. Это выражается в размещении материалов на популярных интернет-платформах, их содержание направлено на разжигание религиозной, этнической розни, включает призывы к осуществлению экстремистской деятельности. Данные люди публикуют посты открыто, со своих аккаунтов, в большинстве случаев, не осознавая того факта, что они совершают преступление. В этом случае не приходится говорить ни о каких конспирации и сокрытии следов.

4 Васкэ Е. В. Психическое и психологическое воздействие в уголовном процессе - к определению понятий // Российский психологический журнал. 2010. № 1. С. 25-36.

5 Гайворонская А. А. Психосемантическая концепция экстремизма. Смоленск : ВА ВПВО BC PФ, 2018. C. 50. 
2. Искатели приключений. Для людей этого типа характерен поиск сильных ощущений, «адреналина». У этих лиц нарушены процессы социализации. Не причисляя себя к каким-либо экстремистским движениям, они не являются носителями экстремистской идеологии, но восприимчивы к идеям экстремистского плана и, как правило, через них осуществляется экстремистская деятельность.

3. Ненормативный тип. Этих людей условно можно обозначить как явно экстремистский тип. У них ярко выражены маргинальные поведенческие установки. Это может проявляться в полном игнорировании законов, норм и традиций общества6.

Установление принадлежности лиц к той или иной группе связано с такими характеристиками, как возраст, пол, образование, религиозная, этническая и политическая идентичность. Например, для первой группы (просоциальный/идеалистический тип) свойственны следующие характеристики: фанатичная преданность религии, партии или этнической группе / национальности, стереотипность мышления, ксенофобские установки. Эти лица используют в интернет-пространстве креолизованные тексты, плакатные листовки. Они участвуют в дискуссиях, используют фрейковые новости для создания провокационных ситуаций. Представлена эта группа лицами мужского пола, имеющими хорошее образование, разного возрастного состава.

Для второй группы (искатели приключений) выделяются такие характеристики: нарциссизм, инфантилизм, пассионарность. У представителей этой группы выражена потребность в идеализации, романтизации своей деятельности, для них характерны поиск такого героя, как Сталин или Че Гевара, обращение к былинным героям (Евпатий Коловрат, Илья Муромец и др.). Как правило, они увлечены историей, используют исторические данные, артефракты в своих целях, выставляют в социальных сетях специальные видеозаписи исторических событий (немецкие солдаты ВОВ) с акцентом на демонстрацию силы. Используют подборки «бравурных» музыкальных произведений, в основном маршей. В этой группе преобладают представители мужского пола, в основном принадлежащие к молодежной группе.

В третьей группе (ненормативный тип) выделяют характеристики: неуважение к чужим границам, «правдорубство», отсутствие эмпатии. Эти лица выставляют в социальных сетях специально подобранные видеозаписи драк, убийств, для того чтобы вызвать страх при просматривании контента. Они позиционируют идею: «Мне можно все». Мужской и женский пол представлен одинаково, образование среднее, поверхностное.

Для каждого типа лиц с экстремистской направленностью возможно применить психологические приемы, которые учитывают психологическое состояние допрашиваемого и выступают такими раздражителями (триггерами), которые помогают выйти на установление психологического контакта для получения показаний без сокрытия или искажения (см. табл. 1).

6 Холопова Е. Н., Гайворонская А. А., Прейбис А. А. Выявление признаков экстремистской направленности в информационном пространстве // Библиотека криминалиста. Научный журнал. 2017. Вып. № 4 (33). С. 216-226. 
Приемы проведения допроса для каждого типа лиц с экстремистской направленностью

\begin{tabular}{|c|l|l|}
\hline $\begin{array}{c}\text { Tипология } \\
\text { лиц }\end{array}$ & \multicolumn{1}{|c|}{ Приемы } & \multicolumn{1}{|c|}{ Вопросы } \\
\hline $\begin{array}{c}\text { Просоциаль- } \\
\text { ный/идеали- } \\
\text { стический }\end{array}$ & $\begin{array}{l}\text { Дать выход эмоциям, чув- } \\
\text { ствам. } \\
\text { Показать положительное } \\
\text { отношение к личности }\end{array}$ & $\begin{array}{l}\text { Вы понимали, чем могла закончить- } \\
\text { ся эта деятельность? } \\
\text { Откуда у вас возник интерес к исто- } \\
\text { рическим событиям? }\end{array}$ \\
\hline $\begin{array}{c}\text { Искатели при- } \\
\text { ключений }\end{array}$ & $\begin{array}{l}\text { Обмен позициями. } \\
\text { Настройка на сотрудниче- } \\
\text { ство }\end{array}$ & $\begin{array}{l}\text { Чьи идеи помогли вам сформиро- } \\
\text { вать ваши взглдды? } \\
\text { Какую музыку вы любите? }\end{array}$ \\
\hline $\begin{array}{c}\text { Ненорматив- } \\
\text { ный тип }\end{array}$ & $\begin{array}{l}\text { Обнаженная агрессия. } \\
\text { Вмешательство «авторитет- } \\
\text { ного третьего» }\end{array}$ & $\begin{array}{l}\text { В детстве вы подвергались наси- } \\
\text { лию? } \\
\text { Среди ваших знакомых есть ли люди } \\
\text { со степенью доктора наук? }\end{array}$ \\
\hline
\end{tabular}

Поясним приведенные приемы проведения допроса:

- дать выход эмоциям, чувствам - значит дать возможность высказать все, что у человека наболело и тем самым снизить эмоционально-психологическое напряжение;

- показать положительное отношение к личности - оказать поддержку, дать положительную характеристику личным качествам;

- обмен позициями предполагает предложение высказать претензии с позиции оппонентов допрашиваемого лица. Этот прием позволяет ему выйти за пределы личных обид, целей, интересов;

- «настройка» означает подачу сигналов типа «мы одной крови». Копирование жестов, тональности голоса, стиля общения допрашиваемого, «вычисление» приоритетной модальности (аудиал, визуал, кинестетик, дигитал) помогает установить психологический контакт;

- обнаженная агрессия требует дать выговориться о наболевшем, о тех событиях, которые способствовали включению лица в противоправную деятельность;

- вмешательство «авторитетного третьего» предполагает привлечение третьего лица, пользующегося доверием допрашиваемого. Используя его влияние на потерпевшего, можно создать условия для дачи показаний по делу.

Представленные приемы возможно комбинировать. При проведении допроса по преступлениям экстремистской направленности, совершенным в сети Интернет, рекомендуется применять следующий примерный перечень вопросов.

1. Простые и прямые (закрытые) вопросы для получения конкретной информации или согласия/несогласия с предложенным содержанием вопроса. Данные вопросы подтверждают предположения или уточняют информацию. Любое повествовательное предложение можно превратить в закрытый вопрос, путем интонационного повышения к концу предложения. Примерный перечень вопросов представлен в табл. 2 . 
Простые и прямые (закрытые) вопросы

\begin{tabular}{|l|l|}
\hline Простые и прямые (закрытые) вопросы & \multicolumn{1}{|c|}{ Оценка следователем фактора } \\
\hline $\begin{array}{l}\text { Когда вы разместили материалы } \\
\text { на сайте? }\end{array}$ & $\begin{array}{l}\text { Уточнение информации (число, дата, } \\
\text { время) }\end{array}$ \\
\hline $\begin{array}{l}\text { Кто еще принимал участие в } \\
\text { размещении материалов на сайте? }\end{array}$ & $\begin{array}{l}\text { Подтверждение предположения (имена, } \\
\text { фамилии) }\end{array}$ \\
\hline $\begin{array}{l}\text { Вы знали о содержании данных } \\
\text { материалов? }\end{array}$ & Согласие/несогласие (да/нет) \\
\hline
\end{tabular}

Эти вопросы могут вызывать сопротивление у допрашиваемого и способствовать сокрытию/искажению получаемой информации. Для получения сведений при ответе на такие вопросы применяется психологический прием: если фригурант сказал «да» и замолчал, можно наклониться немного вперед и ждать, не говоря ни слова, выдержать паузу в такой позе. Вскоре допрашиваемый сам начнет пояснять свой ответ, чтобы эту паузу заполнить. Данные вопросы являются средством реконструкции изучаемых событий. Закрытые вопросы оказывают на допрашиваемого психологическое давление высокой степени, заставляя изменить мнение и перейти к конкретному ответу «да» или «нет». Привлекательность закрытых вопросов в том, что их легко задавать и на них нетрудно отвечать.

2. Сложные, непрямые (открытые) вопросы, требующие развернутого ответа, предназначены для создания атмосферы доверия, для того чтобы разговорить фригуранта, понять, что стоит за его утверждениями. Не рекомендуется задавать эти вопросы в конце допроса и использовать отвлеченные темы. Открытые вопросы задаются с помощью вопросительных слов, которые ставятся в начале предложения (почему, как, когда, в связи с чем и т.д.). Примерный перечень вопросов представлен в табл. 3 .

Таблица 3

\section{Сложные, непрямые (открытые) вопросы}

\begin{tabular}{|c|c|}
\hline $\begin{array}{c}\text { Сложные, непрямые (открытые) } \\
\text { вопросы }\end{array}$ & Оценка следователем фактора \\
\hline $\begin{array}{l}\text { Каких результатов вы ожидали, когда } \\
\text { совершали эти действия? }\end{array}$ & Выяснение общего представления \\
\hline $\begin{array}{l}\text { Расскажите о подробностях происше- } \\
\text { ствия и как бы вы могли это объяснить? }\end{array}$ & Изучение ситуации \\
\hline $\begin{array}{l}\text { Расскажите, почему идеи экстремизма } \\
\text { привлекательны для вас? }\end{array}$ & $\begin{array}{l}\text { Установление психологического } \\
\text { контакта }\end{array}$ \\
\hline
\end{tabular}

Ответы на эти вопросы должны быть от первого лица, связаны с прошлым, соответствовать временно́й последовательности. В содержании ответа оцениваются конкретные и точные детали, подробности. В ответе на задаваемые вопросы 
могут проявляться оговорки, «проговоры», речевые ошибки. Открытые вопросы оказывают наименьшее психологическое давление. Положительное значение и выражается в том, что допрашиваемый отвечает на вопрос без ограничений; ему представлена возможность добровольно передать информацию, свободно говорить о своих чувствах, комментировать события; допрашиваемый ориентируется на размышления, анализ своих поступков.

Отрицательное значение выражается в том, что данные вопросы могут спровоцировать длинный ответ, поэтому не всегда применимы в условиях лимита времени; способны создать затруднительное положение для фригуранта, не привыкшего отвечать на общие вопросы; могут вызвать сбивчивый и сумбурный ответ, сложный для понимания.

3. Альтернативные вопросы - это вопросы, которые предполагают два ответа или более. Цель задавания вопросов - представить варианты выбора, понять области интересов допрашиваемого. Задается альтернативный вопрос при помощи двух или более вариантов (для выбора между этими вариантами) и используется союз «или». Альтернативные вопросы ставят допрашиваемого перед необходимостью решения, но задают ему пространство для выбора ответа. В этом смысле альтернативные вопросы дают допрашиваемому более высокую психологическую безопасность, чем закрытые вопросы. Примерный перечень вопросов представлен в табл. 4 .

Таблица 4

\section{Альтернативные вопросы на «выбор без выбора»}

\begin{tabular}{|l|l|}
\hline \multicolumn{1}{|c|}{$\begin{array}{c}\text { Альтернативные вопросы } \\
\text { на «выбор без выбора» }\end{array}$} & \multicolumn{1}{|c|}{ Оценка следователем фактора } \\
\hline $\begin{array}{l}\text { Вы использовали платный } \\
\text { или бесплатный прокси-сервер? }\end{array}$ & Уточнение места \\
\hline $\begin{array}{l}\text { Вы поместили на сайт материалы за } \\
\text { один раз или по частям? }\end{array}$ & $\begin{array}{l}\text { Уточнение деталей, } \\
\text { выяснение подробностей }\end{array}$ \\
\hline $\begin{array}{l}\text { Вы сначала все расскажете } \\
\text { или запишите на бумагу? }\end{array}$ & Сбор информации \\
\hline
\end{tabular}

Альтернативные вопросы описывают время, место, очередность, последовательность и характер действий. Альтернативные вопросы используются для работы с возражениями.

Таким образом, на основе проведенных исследований были предложены наиболее целесообразные тактические приемы способствующие установлению психологического контакта с допрашиваемым. Для ведения допроса лиц экстремистской направленности (идеалистический тип, искатели приключений, асоциальный тип) описаны тактические приемы с примерным перечнем вопросов, которые предназначены для достижения взаимопонимания между следователем и фигурантом, при котором последний, независимо от складывающейся при допросе ситуации, проявляет сотрудничество со следователем и представляет информацию об обстоятельствах дела без искажения и сокрытия. 


\section{БИБЛИОГРАФИЯ}

1. Васкэ Е. В. Психическое и психологическое воздействие в уголовном процессе - к определению понятий // Российский психологический журнал. 2010. - № 1. - С. 25-36.

2. Гайворонская A. А. Психосемантическая концепция экстремизма. - Смоленск : ВА ВПВО ВС РФ, 2018. - 50 с.

3. Козлова Н. И. Психологические приемы допроса при расследовании оскорблений // Психопедагогика в правоохранительных органах. — 2010. — № 4 (43). - C. 24-26.

4. Комиссаров В. И., Комиссарова Я. В. Тактика допроса и очной ставки // Криминалистика : учебник (уровень специалитета) / под ред. А. И. Бастрыкина, Е. П. Ищенко, Я. В. Комиссаровой. - М. : Проспект, 2019. - С. 390-409.

5. Комиссарова Я. В. Понятие и классификация следов в криминалистике // Вестник Университета имени О.Е. Кутафина (МГЮА). —2019. — № 3 (55). C. $131-141$.

6. Першин А. Н., Сидорова К. С. Криминалистические основы установления пользователя информационно-телекоммуникационной сети Интернет // Вестник Университета имени О.Е. Кутафина (МГЮА). — 2019. - № 3 (55). C. $82-94$.

7. Черевко И. М., Никонович С. Л., Бекетов В. А. Системный подход к психологическому воздействию следователя на допрашиваемого // Крымский научный вестник. - 2017. — № 1. - С. 75-89. 